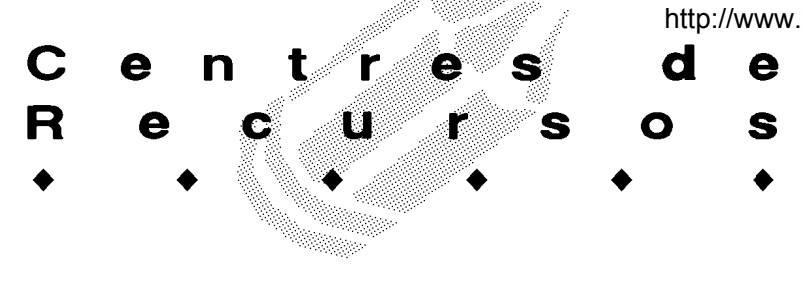

\title{
EL CENTRE DE RECURSOS PEDAGÒGICS DEL BAIX CAMP
}

\section{L'equip del CRP del Baix Camp}

\section{Presentació}

El Centre de Recursos Pedagògics (CRP) del Baix Camp està situat a Reus, al barri Gaudí, on també es troben altres serveis com l'Oficina Gestora, el Servei d'Ensenyament del Català (SEDEC), l'Equip d'Assessorament Psicopedagògic (EAP) T-09 i la Inspecció Tècnica d'Ensenyament. El seu àmbit comprèn tots els centres d'ensenyament no universitari, tant públics com concertats.

Té un historial d'uns 13 anys. Es va crear al mes d'abril de 1984 en unes aules del pis superior del C.P. "Ciutat de Reus». Actualment té un local nou i ampli als baixos d'aquest edifici.

El CRP dóna suport als centres d'ensenyament d'Educació Infantil, Primària i Secundària de Reus i de la resta de comarca, tenint en compte que hi ha dues zones rurals en què estan agrupats els centres de primària:

1. La ZER Baix Camp Nord, amb els centres d'Almoster, l'Aleixar, Alforja, Castellvell del Camp i Riudecols.

2. La ZER Baix Camp Sud, amb Botarell, Duesaigües, Pratdip, Riudecanyes, Vilanova d'Escornalbou i Vinyols i els Arcs.

3. La resta de pobles de la comarca: Les Borges del Camp, Cambrils, Montbrió del Camp, Mont-roig del Camp, Riudoms, la Selva del Camp, Vandellòs i l'Hospitalet de l'Infant.

Quant a les xifres, podem dir que donem resposta a 39 centres públics, amb 568 aules $i 11$ centres concertats, amb 257 aules, tots ells d'Educació Primària.

A Secundària abastem 14 centres públics, amb 607 aules i 9 de concertats, amb 95 aules.

\section{Formació Permanent}

La formació permanent del professorat té com a objectius:

- Contribuir a l'increment de la qualitat de l'ensenyament, incidint en la millora de la pràctica docent i en l'organització dels centres.

- Oferir un marc d'actuacions d'acord amb les necessitats del sistema i amb els interessos del professorat i dels centres.

- Afavorir la programació territorial, amb criteris descentralitzadors i participatius de les activitats

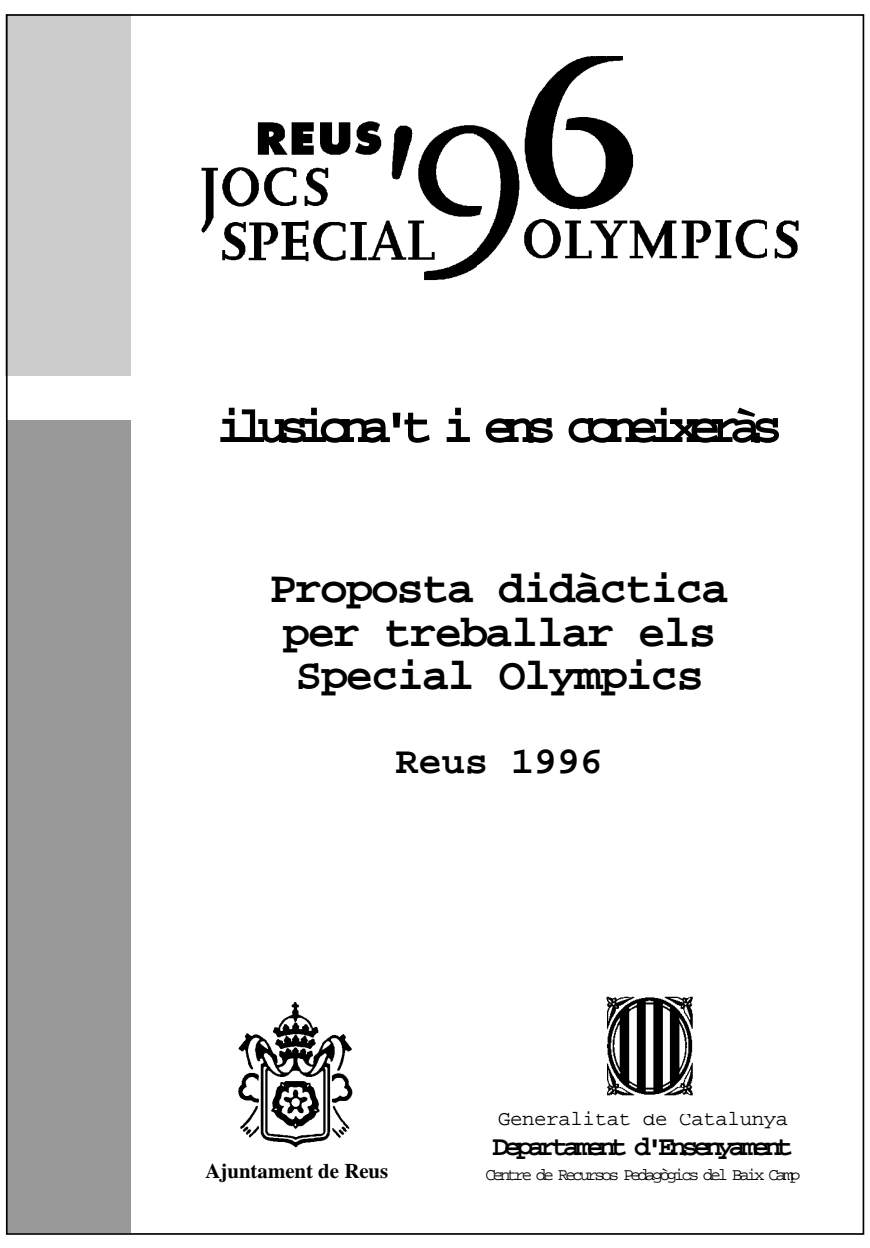

de Formació Permanent.

El Departament d'Ensenyament encarrega una part de la formació permanent a les universitats, en el nostre cas, a la Rovira i Virgili, que organitza i gestiona l'ICE, i l'altra part la porten directament els programes i serveis que depenen directament del Departament: Programa d'Informàtica Educativa (PIE), Programa de Mitjans Audiovisuals (PMAV), Servei d'Ensenyament del Català (SEDEC), Programa d'Educació per a la Salut (PESE), Centre de Documentació i Experimentació en Ciències (CEDEC). 


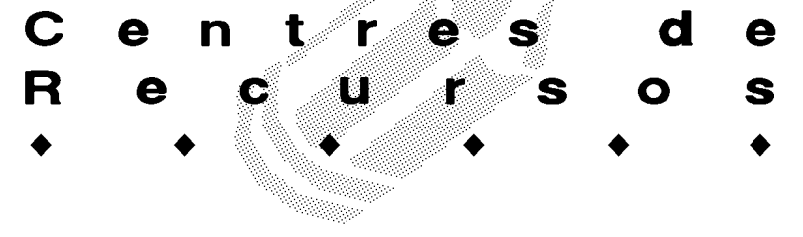

Per tal de poder coordinar la formació del professorat es varen crear les comissions comarcals de Pla de Zona, en les quals la representació dels centres serà com a mínim del $50 \%$ i com a màxim del $60 \%$ de la composició total de la comissió. D'aquesta comissió, i a partir d'unes propostes aportades des del mateix Departament d'Ensenyament i des de la detecció de necessitats que el CRP ha realitzat a la comarca, surten les activitats que es poden realitzar durant cada curs escolar. El CRP també és l'encarregat de fer les inscripcions, de dur a terme una part del seguiment -conjuntament amb la inspecció- de promoure la seva difusió i de donar suport a la seva infraestructura.

Enguany, dins del Pla de Formació Permanent de la zona, s'han ofert activitats diverses: cursos, mòduls d'aprofundiment, seminaris, grups de treball, assessorament a centres i conferències. D'aquesta manera cada professional i cada centre pot escollir el tipus d'activitat més adient per a les seves necessitats i els seus interessos.

A causa del moment de canvis profunds que viu l'ensenyament dins el curs escolar actual, la modalitat que més ha incentivat els professionals d'ensenyament és l'assessorament a centres, ja que està encaminat a la millora global d'un centre determinat i és un recurs per a resoldre situacions concretes que es plantegen per necessitats específiques d'un centre, atenent la seva singularitat quant a alumnat, professorat i context social.

Dins la nostra comarca hem de parlar de l'elevada participació dels professionals d'ensenyament en aquestes activitats i en d'altres que ofereix el Departament d'Ensenyament, fet que demostra l'interès i preocupació dels docents per a la millora professional i que coincideix plenament amb els objectius del Pla d'Activitats de Formació Permanent de la Zona.

\section{Recursos educatius que oferim}

Servei de documentació

El volum de material disponible al CRP ha anat augmentant progressivament i d'una manera considerable els darrers anys. Actualment disposem de més de 1500 títols de vídeos educatius aplicables a totes les matèries curriculars i als diferents nivells educatius. El nombre de llibres de la biblioteca sobrepassa els quatre mil i també tenim colleccions de diapositives, discos i cassets.

Tot això va propiciar que des de fa sis cursos s'endegués un procés d'informatització de tot aquest material que forma la mediateca. Es van elaborar unes fitxes molt completes de cada recurs ( llibre, dossiers, vídeo). Tota aquesta tasca ha estat coordinada des del Servei de Gestió de Programes Educatius per repartir el treball d'elaboració de fitxes per a tots el CRPs de Catalunya.
Aquest procés està pràcticament acabat $\mathrm{i}$ ja disposem d'un CD-Rom amb més de 35000 fitxes de tot el material disponible a tots el CRPs de Catalunya.

A partir d'aquest procés informàtic es poden elaborar catàlegs molt diversos: per matèries, nivells, temàtica, etc.

També fa molt àgil la consulta per part del professorat de qualsevol recurs. Es pot trobar informació detallada sobre l'autor, títol, característiques, nivell educatiu recomanat, principals temes que tracta i finalment un bon resum del seu contingut.

El curs 94 / 95 vam elaborar un catàleg dels vídeos disponibles a la nostra mediateca que ha estat de molta utilitat i que s'anirà actualitzant amb la inclusió de les novetats.

\section{Servei de reprografia}

Al CRP disposem de fotocopiadora i multicopista electrònica de gran utilitat per a editar d'una manera econòmica, ràpida i amb bona qualitat: dossiers, cartells, fitxes, revistes escolars, etc.

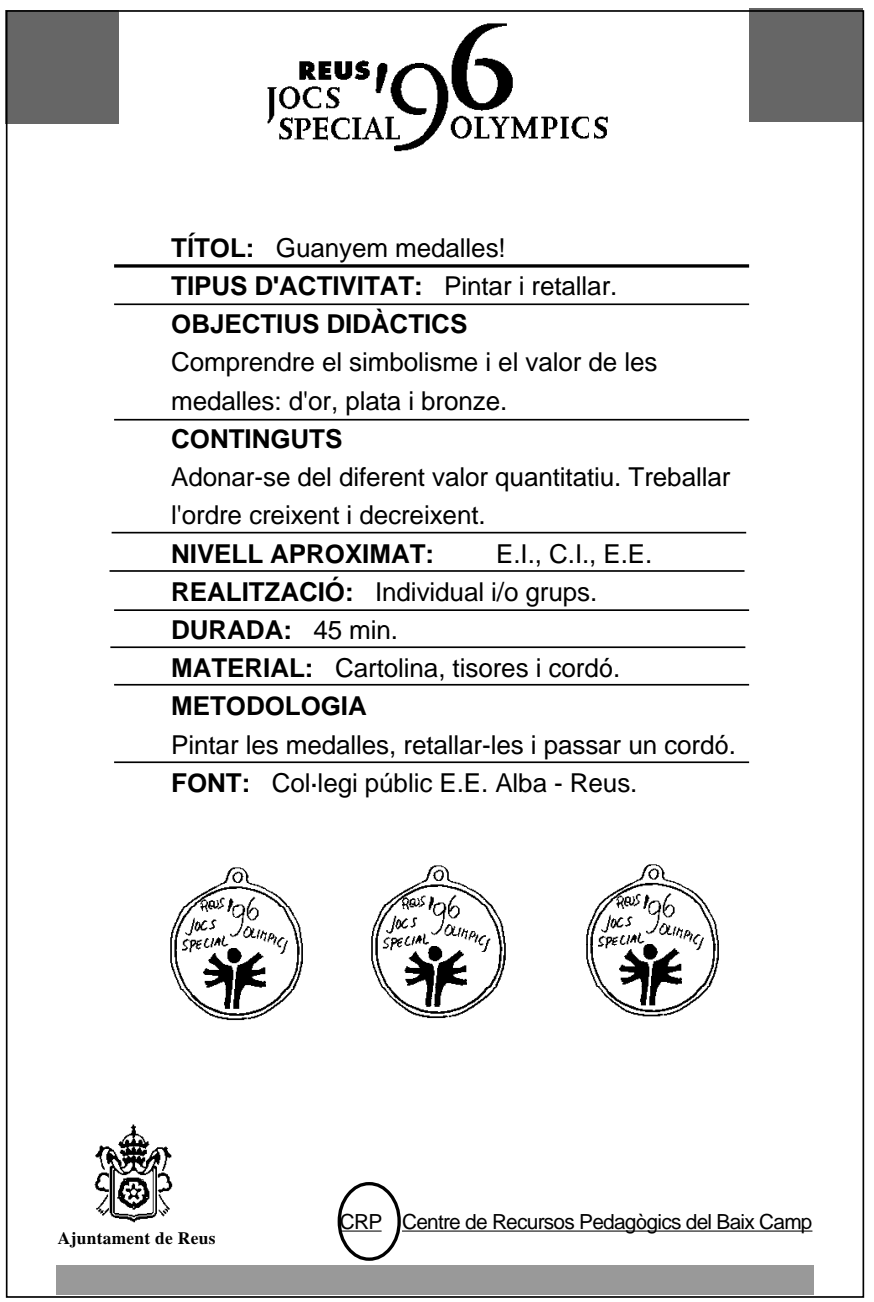




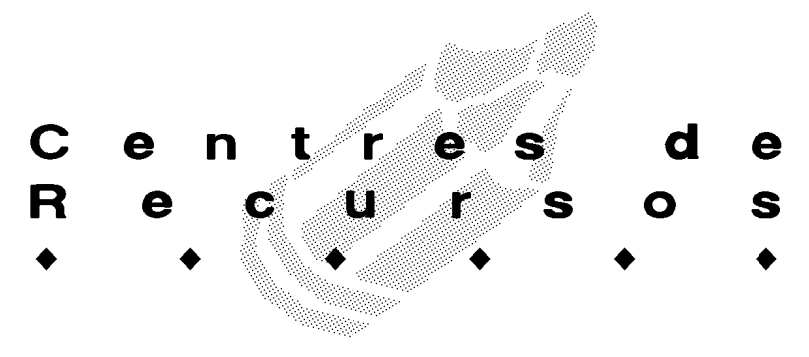

El CRP també ofereix aparells per a plastificar, enquadernar, cisellar, etc.

Aparells audiovisuals

A part de l'equip instal-lat al CRP per a visionar vídeos, disposem de molts aparells que es poden deixar en préstec als centres escolars: TV, magnetoscopi, càmera de vídeo, taula de mescles, equips de so, projector de diapositives, retroprojectors, projector de cossos opacs, etc.

\section{Full informatiu}

Des del CRP elaborem un full informatiu adreçat a tot el professorat per a donar notícia de les activitats que realitzem, material nou que arriba al centre i tot tipus d'informacions que poden ser d'interès per al professorat: concursos, exposicions, cursos no inclosos al Pla de Formació Permanent, conferències, etc.

\section{Exposicions}

Al centre hem organitzat diferents tipus d'exposicions monogràfiques de material, llibres de text, crèdits, treballs de plàstica de diferents centres, etc.

L'eminent parvulista, Sra. Cèlia Artiga, va fer donació del seu material al CRP amb motiu de la seva jubilació. Durant el curs 94 / 95 es va instal-lar al hall dels Serveis Educatius del Baix Camp una exposició permanent amb una tria d'aquest material de parvulari.

\section{Publicacions}

Des del CRP s'han editat i repartit per a tots els centres educatius de la comarca diferents dossiers elaborats per professionals de la zona a nivell general o per mitjà de seminaris o grups de treball.

Les darreres publicacions han estat una guia de recursos educatius del Baix Camp i, a començaments d'aquest curs, un dossier de fitxes didàctiques amb motiu de la celebració a Reus del Jocs Special Olympics.

Com a projectes més immediats, estem treballant en l'edició d'un vídeo i l'elaboració d'una unitat de programació dels vitralls modernistes de Reus.

\section{Altres col-laboracions}

A partir de les activitats de suport als centres docents no universitaris (exposicions, tallers...) mantenim relacions de col-laboració amb altres organismes i institucions: amb CRP's d'altres comarques, amb l'Ajuntament, Diputació, Consell Comarcal... i portem a terme activitats concretes: mostra de teatre, programes de salut... També col.laborem amb entitats que amb voluntat pedagògica porten a terme formació; la majoria porten ensenyaments no reglats: tallers ocupacionals, esplais, centres cívics, Associació contra la Sida, o el mateix Institut Municipal de Formació i Empresa de l'Ajuntament, el Centre de Lectura...
El nostre Servei també col-labora amb la Universitat Rovira i Virgili assessorant en els materials que deixem en préstec als estudiants de la Facultat de Ciències de l'Educació i Psicologia. També portem a terme col-laboracions puntuals en moments que sorgeix una necessitat a la comarca, per exemple en ocasió de la celebració dels Jocs Special Olympics a Reus, que es van dur a terme el passat mes de novembre. Amb la finalitat d'apropar tots els alumnes dels centres docents a la realitat del món dels discapacitats psíquics, es va constituir al CRP un grup de treball per elaborar un dossier amb fitxes de treball adreçades als alumnes de les diverses etapes, per tal de treballar-lo abans de la celebració dels Jocs i poder-hi participar més plenament, potenciant a la vegada la integració de les persones discapacitades en el món ordinari i consolidant la integració d'aquests alumnes en el món escolar i social.

\section{Mostra de teatre}

Els educadors saben la força formativa que té el teatre dintre del món de l'ensenyament. A banda, també és una manera d'omplir el lleure dels escolars, amb la particularitat que això es fa entre la diversió i una disciplina que comporta la interpretació dramàtica.

La nostra comarca va ser pionera a promoure la iniciativa del teatre a l'escola.

La 1a edició de la Mostra de Teatre Infantil Reus Baix Camp es va fer l'any 1981; enguany arribem a la XVII edició de la mostra. Aquest curs està previst de realitzar-lo del 6 al 14 de març, amb un total de 30 obres. Cal destacar la tasca que va portar a terme la Reddis Unió Mútua durant els quatre primers anys en la coordinació de les escoles que organitzaven aquesta activitat al centre. A partir d'aleshores la mostra està patrocinada per la Diputació de Tarragona, amb la col-laboració de diferents institucions públiques i privades. Es gestiona per una comissió de la qual formen part mestres, Centre de Recursos i representants de les entitats col-laboradores. Hi participen les escoles de Reus i comarca amb els professors corresponents. Té una durada de vuit dies, durant els quals es fan les representacions de les diferents escoles. El dia de la cloenda es fa el lliurament de premis als alumnes-actors i una representació a càrrec del col-lectiu de mestres. Aquest col-lectiu està format per un grup de mestres que assagen durant el curs l'obra que serà representada el dia de la cloenda. 